\title{
Níveis de cálcio no desempenho de machos reprodutores de corte com e sem crista
}

\author{
Calcium levels in the performance of broiler breeder males with and without comb
}

\author{
Alexandre Pires Rosa ${ }^{\mathrm{I}}$ Márcio Pilecco ${ }^{\mathrm{II}}$ Walter Lucca ${ }^{\mathrm{III}}$ Rodrigo Uttpatel ${ }^{\mathrm{III}}$
}

\section{RESUMO}

O objetivo deste experimento foi avaliar o efeito do nível de cálcio na dieta sobre o peso corporal e as variáveis reprodutivas (volume de sêmen, número de células espermáticas e fertilidade) em reprodutores de corte machos com ou sem crista. Foram utilizados 32 machos Cobb 500, 50\% com crista inteira e $50 \%$ sem crista. $O$ delineamento experimental utilizado foi o inteiramente casualizado, com esquema fatorial $2 \times 2$, duas condições de crista (com e sem) e dois níveis de cálcio $(0,90$ e $1,35 \%)$. O sêmen foi coletado pelo método americano, e o número de células espermáticas foi determinado em câmara de Neubauer. $\mathrm{Na} 42^{2}$, na $43^{a}$ e na $44^{\underline{a}}$ semana de idade dos machos, 48 fêmeas para cada tratamento foram inseminadas artificialmente. As inseminações foram realizadas duas vezes por semana, com sêmen fresco, na dose de 0,05mL. Depois de 21 dias de incubação, os ovos não eclodidos foram quebrados e examinados macroscopicamente para análise da fertilidade. Os machos alimentados com 0,90 e 1,35\% de cálcio nas dietas tiveram pesos similares. Além disso, na $31^{a}$ a semana de idade, machos com crista que receberam dietas com 0,90\% de cálcio apresentaram maior número de células espermáticas $\left(3,00 \times 10^{6}\right.$ $0,90 \%$ com crista contra $9,46 \times 10^{5} 0,90 \%$ sem crista). O nivel de cálcio de 0,90\% foi suficiente para promover um bom desempenho reprodutivo em reprodutores de corte machos. Machos com crista inteira tiveram melhor fertilidade que os demais machos sem crista.

Palavras-chave: fertilidade, avicultura, células espermáticas, volume de sêmen.

\section{ABSTRACT}

The objective of this trial was to evaluate the effect of dietary calcium on the body weight and reproductive variables (semen volume, number of spermatic cells and fertility) in broiler breeder males with or without comb. A total of 32 males Cobb 500 were used, 50\% combed and 50\% not combed males. The experimental design was completely randomized in a factorial $2 \times 2$, with two comb conditions (with or without) and two levels of calcium $(0.90$ e $1.35 \%)$. Semen was collected using the American methods and number of spermatic cells was determined in a Neubauer chamber. At 42, 43 and 44 weeks of age, 48 females were artificially inseminated by treatment, twice a week, with dosage of $0.05 \mathrm{~mL}$ fresh semen. After 21 day of incubation the unhatched eggs were broken and examined macroscopically to analyze the fertility. The roosters that were fed with 0.90 and $1.35 \%$ of calcium on the diets had similar weight. Besides, at $31^{\text {st }}$ of age, males with comb that were fed with $0.90 \%$ of calcium on the diet presented higher number of spermatic cells $\left(3.00 \times 10^{6} 0.90 \%\right.$ with comb intact against $9.46 \times 10^{5} 0.90 \%$ without comb). The $0.90 \%$ calcium level was enough to promote a good reproductive performance in broiler breeder males. Males with comb intact had better fertility than the males without comb.

Key words: fertility, poultry, spermatic cells, semen volume.

\section{INTRODUÇÃO}

Em virtude da importância do rendimento de carcaça do frango de corte, tem sido realizada alta pressão de seleção genética na linha macho em matrizes, com o objetivo de melhorar seu desempenho e assim transmitir tais características aos seus descendentes. Nesse sentido, a nutrição tem considerável responsabilidade pelo sucesso da avicultura. O manejo nutricional da matriz tem recebido maior ênfase, enquanto a nutrição dos reprodutores machos tem sido relegada ao segundo plano. Apesar de a proporção de machos representar apenas $10 \%$ em relação à das

'Departamento de Zootecnia, Universidade Federal de Santa Maria (UFSM), Santa Maria, RS, Brasil.

"Curso de Zootecnia, UFSM, 97015-040, Santa Maria, RS, Brasil. E-mail: mpilecco@yahoo.com.br. Autor para correspondência. IIIPrograma de Pós-graduação em Zootecnia, UFSM, Santa Maria, RS, Brasil. 
fêmeas, os machos contribuem com $50 \%$ da carga genética do plantel e são fundamentais para a fertilidade deste. Entretanto, as informações atuais sobre os fatores nutricionais que influenciam o desempenho reprodutivo não estão de acordo com a importância dos machos no processo reprodutivo (DANIKOWSKI et al., 2002).

Entre os principais nutrientes para as aves, o cálcio é o mineral mais ativo metabolicamente, sendo essencial para uma série de funções metabólicas, principalmente no desenvolvimento da ave. O cálcio é um mineral que atua na formação esquelética, ativação enzimática e secreção de hormônios e de neurotransmissores (VANDER et al., 1990; MACARI et al., 2002). O cálcio é requerido pelas aves para formação e manutenção da estrutura óssea, adequado crescimento e utilização eficiente dos alimentos, formação da casca do ovo, transmissão de impulsos nervosos, coagulação sanguínea, contração muscular, ativador de sistemas enzimáticos e envolvimento com a secreção de diferentes hormônios (VARGAS JUNIOR et al., 2003; SÁ et al., 2004).

Dietas com altos níveis de cálcio são justificadas para galinhas em fase de produção de ovos. Porém, altos níveis de cálcio, fornecidos no período reprodutivo, desencadeiam problemas renais (VALLE, 1999), bem como impedem a absorção de alguns minerais, como manganês, zinco e magnésio, afetando dessa forma o desempenho dos galos (WALDROUP, 1996). Exames histopatológicos indicaram nefrose, gota visceral, deposição de urato de cálcio nos ureteres e mortalidade de até 20\% (SCOTT et al., 1982).

Pesquisas que investigam o efeito do cálcio dietético para galos são limitadas. Estudando níveis crescentes de cálcio para galos em dois experimentos, WILSON et al. (1969) observaram uma redução no volume seminal com a utilização de $0,50,1,00,1,5$ e $2,0 \%$ de cálcio na dieta, não registrando efeitos dos níveis de cálcio sobre a concentração espermática, percentagem de espermatozoides mortos, fertilidade, eclodibilidade ou percentagem de cinzas nos ossos. NORRIS et al. (1971) observaram que o fornecimento de dieta contendo $0,0035 \%$ de cálcio e $0,1 \%$ de fósforo total para galos Leghorn resultou em teor normal de cinzas ósseas. Trabalhando com galos Leghorn submetidos a muda forçada, LOPES et al. (1993) observaram um efeito adverso de altos níveis de cálcio dietético $(3,5 \%)$ sobre o volume seminal, o número de espermatozoides por ejaculado, o vigor e a motilidade espermática, mas não na fertilidade e no peso corporal. Os autores também verificaram redução no teor de cinzas ósseas em galos que receberam $1 \%$ de cálcio, comparativamente a galos que receberam $3,5 \%$ de cálcio. Em reprodutores de linhagem de corte, KAPPLEMAN et al. (1982) constataram que os níveis de cálcio variando de 0,5 a $7 \mathrm{~g} \mathrm{dia}^{-1}$ não afetaram o desempenho reprodutivo dos galos.

Níveis de 0,92 a $0,96 \%$ de cálcio são satisfatórios para machos Cornish durante a fase de reprodução (ELGUEIRA, 1986). Já McDANIEL et al. (1985) recomenda níveis de 0,8 a 1,0\% de cálcio, e WILSON et al. (1969) recomendam níveis de $0,96 \%$ de cálcio. ROSTAGNO et al. (2005) citam que níveis de cálcio de 0,65\% para galos atende as necessidades reprodutivas em todos os aspectos. HONMA (1992) mencionou que o nível de cálcio adequado para reprodutores de corte machos deve ser abaixo de $2,0 \%$.

O corte parcial e total da crista do macho é realizado como prática rotineira em empresas avícolas. A retirada da crista minimiza o problema de necrose desta, evitando também perdas de machos quando há tentativa de busca de alimentos nos comedouros das fêmeas (FERRUFINO, 1996). Por outro lado, machos com crista inteira dominam as fêmeas com maior facilidade no início do ciclo reprodutivo, permitindo maior fertilidade na primeira etapa reprodutiva. Além disso, a permanência da crista facilita a alimentação separada entre os sexos na reprodução e ajuda na dissipação de calor nas regiões de clima quente (FERRUFINO, 1996). Constatou-se que ovos oriundos de fêmeas acasaladas com machos com crista obtiveram maior fertilidade na 32a semana, e que esses machos apresentaram maior dominância sobre as fêmeas, influenciando positivamente a fertilidade no início do ciclo produtivo (FERRUFINO, 1996).

Devido às controvérsias relacionando manejo com nutrição, o objetivo deste estudo foi avaliar dois níveis de cálcio, comumente usados em rações fornecidas a matrizes fêmeas, para reprodutores de corte, com e sem crista, quanto às variáveis peso corporal, volume de sêmen, número de células espermáticas e fertilidade.

\section{MATERIAL E MÉTODOS}

Para a execução do experimento, foram adquiridos 32 reprodutores da linhagem Cobb 500, com um dia de idade, sendo $50 \%$ com crista e os demais sem crista. A ausência da crista foi devida à cauterização realizada no incubatório da Agrogen Desenvolvimento Genético Ltda (Montenegro, no Rio Grande do Sul (RS)).

No período pré-experimental, ou seja, na fase de cria e recria (1a a 22a semana), todas as aves receberam os mesmos níveis nutricionais e as mesmas condições de manejo, conforme manual da linhagem. No incubatório, as aves receberam a vacina contra a doença de Marek e cauterização da espora. A debicagem ocorreu no 6o dia de idade e a alimentação, durante as três primeiras semanas, foi ad libitum e depois restrita 
para controlar o peso e a uniformidade das aves (obtida por pesagens semanais). $\mathrm{O}$ incremento alimentar (quantidade diária de ração fornecida) foi realizado buscando manter o peso padrão da linhagem. A seleção dos machos foi realizada na 8aㅡ, na $14^{-a}$ e na $22^{a}$ semana de idade, quando foram realizadas pesagens totais, e as aves agrupadas conforme faixa de peso corporal (leves, médias e pesadas), sendo $33 \%$ de aves para cada categoria de peso. $\mathrm{Na} 22^{\text {a }}$ semana, os machos foram distribuídos em gaiolas metálicas individuais de 0,30x0,40x0,40m (frente, altura, profundidade), dotadas de bebedouro e comedouro, de maneira que cada tratamento conteve o mesmo número de machos nas faixas de peso leve, médio e pesado.

$\mathrm{Na}$ fase experimental, foram utilizadas duas dietas, as quais diferiam somente no nível de cálcio $(0,90$ e $1,35 \%)$. Comumente, alguns avicultores fornecem rações de fêmeas para os machos. O propósito da escolha desses níveis no presente trabalho foi auxiliar o avicultor na escolha da ração de fêmea mais adequada para machos, sem necessidade de fabricar uma ração específica. Como o nível de 0,90\% é a quantidade de cálcio utilizada em dietas na fase de crescimento para matrizes da linhagem COBB 500 e o nível de $1,35 \%$ é o utilizado na fase de pré-postura dessa mesma linhagem, optou-se testar quais desses níveis se adequariam melhor para machos. Essas dietas eram isoproteicas, isoenergéticas, isofosfóricas e isoaminocídicas, conforme tabela 1. Durante o período experimental (22ª a 44ํㅡㄹ semana de idade), a alimentação foi de $125 \mathrm{~g}_{\text {ave }}{ }^{-1} \mathrm{dia}^{-1}$, fornecida diariamente pela manhã, sempre no mesmo horário.

O delineamento experimental foi inteiramente casualizado, em esquema fatorial $2 \times 2$, duas condições de crista (com ou sem) e dois níveis de cálcio $(0,90$ e $1,35 \%)$. Cada tratamento foi constituído de oito repetições, com um macho por unidade experimental. $\mathrm{Na} 24^{\mathrm{a}}$ semana, iniciou-se a coleta dos dados, e a pesagem das aves foi realizada a cada 14 dias. A coleta de sêmen foi realizada nas semanas em que não houve pesagem, ou seja, entre a $25^{\text {a }}$ e $43^{\text {a }}$ semanas, pelo método americano, em que o reprodutor é estimulado por meio de massagem abdominal (BRILLARD, 1992).

O sêmen foi coletado em tubos de ensaio de vidro, com diâmetro de $1,5 \mathrm{~cm}$, graduados em mililitros, padronizados pelo "INMETRO”. A diluição para a contagem das células espermáticas foi de 1 para 200, seguindo a mesma técnica usada para bovinos (BRILLARD, 1992). A diluição do sêmen foi feita com solução salina tamponada de formol para manter a integridade das células, cuja diluição era composta de citrato de sódio $29 \%$ e formol $37 \%$, $(96 \mathrm{~mL}$ de citrato e $4 \mathrm{~mL}$ de formol para $100 \mathrm{~mL}$, respectivamente). A contagem das células foi feita em câmara de Neubauer, em cinco campos de cada lado desta;, após obtenção da média, o valor foi multiplicado pela constante de diluição (10000), e o valor foi expresso em número de células espermáticas por $\mathrm{mm}^{3}$.

A fertilidade foi avaliada por meio da inseminação artificial realizada em 192 fêmeas Barred Plymouth Rock entre a 42- e a 44aㅡ semana, para isso foram realizadas duas inseminações por semana após às $14 \mathrm{~h}$, com sêmen fresco, na dose de $0,05 \mathrm{~mL}$ por ave, conforme ROSA et al. (1995). Os ovos foram coletados quatro vezes ao dia, identificados e fumigados com permanganato de potássio e formol a $37 \%$ e armazenados em sala climatizada $\left(18^{\circ} \mathrm{C}\right.$ e $65 \%$ Umidade Relativa) por um período de no máximo quatro dias até o início da incubação. A fertilidade foi avaliada no $21^{\circ}$ dia de incubação, pela contagem dos pintos nascidos, e avaliação dos ovos não eclodidos. Para a verificação dos ovos fertilizados, fez-se a quebra de todos os ovos não eclodidos calculando-se assim a fertilidade e a eclodibilidade (MARQUES, 1986).

Os dados foram submetidos à análise de variância, ao nível de 5\% de significância, e as médias foram comparadas pelo teste de Tukey, sendo utilizado o pacote estatístico SAS (1997).

\section{RESULTADOS E DISCUSSÃO}

Em todas as semanas do estudo, os machos alimentados com 0,90 e 1,35\% de cálcio nas dietas tiveram pesos corporais similares entre as classes de peso (leve, médio e pesado) $(\mathrm{P} \geq 0,05)$. Esses resultados estão de acordo com os encontrados por HONMA (1992) e RUTZ et al. (1999), os quais também não encontraram influência no peso corporal de reprodutores machos em dietas que tiveram os níveis de cálcio variando entre 0,35 e 3,5\%. Por outro lado, na 34- e 36- - semanas de idade, os machos submetidos a dietas com $1,35 \%$ de cálcio tiveram uma tendência de apresentarem maiores pesos corporais. Pode ser sugerido que essa tendência seja devido a uma diferença mínima em proteína bruta nas dietas dos tratamentos, em que a dieta contendo $1,35 \%$ de cálcio possuía $0,09 \%$ de proteína bruta a mais que a dieta contendo $0,90 \%$ de cálcio (Tabela 1 ).

O volume de sêmen produzido com intervalo de 14 dias não mostrou efeito significativo $(\mathrm{P}>0,05)$ quanto aos níveis de cálcio estudados e ao efeito crista (corte ou não). Na figura 1 , está representado o comportamento do volume de sêmen com máximo volume na 37 - semana. Nos estudos de ELGUEIRA (1986), níveis de 0,92 a 0,96\% de cálcio foram suficientes para atender as exigências de mantença dos galos. Segundo LEESON \& SUMMERS (2000), 0,75\% de cálcio em dietas separadas por sexo é suficiente para 
Tabela 1 - Composição percentual e nutricional das dietas com níveis de cálcio $(0,90$ e 1,35\%).

\begin{tabular}{|c|c|c|}
\hline \multicolumn{3}{|c|}{ Níveis de Cálcio (\%) } \\
\hline Ingredientes & 0,90 & 1,35 \\
\hline Milho & 64,07 & 65,15 \\
\hline Farelo de soja & 17,21 & 18,11 \\
\hline Farelo trigo & 15,0 & 11,80 \\
\hline Fosfato bicálcico & 1,62 & 1,66 \\
\hline Calcário & 1,12 & 2,29 \\
\hline Premix vitamínico e mineral ${ }^{1}$. & 0,50 & 0,50 \\
\hline Sal & 0,40 & 0,40 \\
\hline DL - Metionina & 0,05 & 0,05 \\
\hline L-Treonina & - & 0,01 \\
\hline Total & 100 & 100 \\
\hline \multicolumn{3}{|c|}{ 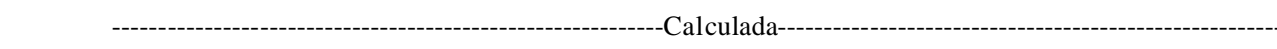 } \\
\hline E Metabolizável (Kcal kg $\left.{ }^{-1}\right)$ & 2850 & 2850 \\
\hline Proteína $(\%)$ & 16,0 & 16,09 \\
\hline Extrato etéreo (\%) & 3,11 & 3,05 \\
\hline Ac. Linolêico (\%) & 1,70 & 1,68 \\
\hline Cálcio (\%) & 0,90 & 1,35 \\
\hline Fósforo (\%) & 0,45 & 0,45 \\
\hline Potássio $(\%)$ & 0,67 & 0,66 \\
\hline Cloro $(\%)$ & 0,28 & 0,28 \\
\hline Ferro $(\mathrm{mg} / \mathrm{g})$ & 0,37 & 0,41 \\
\hline Magnésio (\%) & 0,15 & 0,17 \\
\hline Sódio (\%) & 0,25 & 0,26 \\
\hline Arginina (\%) & 1,01 & 1,01 \\
\hline Glic + Ser $(\%)$ & 1,62 & 1,63 \\
\hline Histidina (\%) & 0,43 & 0,43 \\
\hline Isoleucina (\%) & 0,63 & 0,63 \\
\hline Leucina (\%) & 1,43 & 1,44 \\
\hline Lisina $(\%)$ & 0,77 & 0,78 \\
\hline Metionina (\%) & 0,32 & 0,32 \\
\hline Cistina (\%) & 0,23 & 0,24 \\
\hline Met + Cis (\%) & 0,60 & 0,60 \\
\hline Tirosina (\%) & 0,52 & 0,54 \\
\hline Treonina (\%) & 0,58 & 0,60 \\
\hline Triptofano (\%) & 0,19 & 0,19 \\
\hline Valina (\%) & 0,74 & 0,74 \\
\hline
\end{tabular}

${ }^{1}$ Premix vitamínico e mineral: níveis de garantia por kilograma de premix: Vit. A 2.750.000UI; Vit E 6.000g; Vit $\mathrm{D}_{3}$ 150.000UI; Vit $\mathrm{K}_{3}$ 500mg; Ácido Nicotínico 8.000mg; Vit $\mathrm{B}_{1}$ 550mg; Vit $\mathrm{B}_{12} 3,750 \mu \mathrm{g}$; Vit $\mathrm{B}_{2} 1.875 \mathrm{mg}$; Vit $\mathrm{B}_{6} 1000 \mathrm{mg}$; Ac. Fólico 250mg; Biotina 45mg; Colina 66.000mg; Ác. Pantotênico 3.750mg; Metionina 89.100mg; Cobre 2.400mg; Ferro 12.000mg; Iodo 120mg; Manganês $14.000 \mathrm{mg}$; Selênio 48mg; Zinco $13.000 \mathrm{mg}$.

manter bom desempenho reprodutivo dos galos, e o excesso pode desencadear problemas ligados ao funcionamento dos rins. Já McDANIEL et al. (1985) recomendam níveis de 0,80 a $1,0 \%$ de cálcio. HONMA (1992) constatou que o volume de sêmen diminuiu quando o nível de cálcio foi de 2,0\%.

Quanto à interação níveis de cálcio e presença ou não da crista, houve efeito significativo somente para as variáveis concentração de células espermáticas e fertilidade $(\mathrm{P}<0,05)$. Esses resultados discordam de outros trabalhos (TOWER et al., 1963; LOGAN, 1965), os quais relatam que nenhuma característica produtiva foi afetada pelo corte ou não da crista.

$\mathrm{Na}$ variável concentração das células espermáticas, observaram-se diferenças significativas com relação à interação níveis de cálcio versus crista (presença ou não) ( $\mathrm{P}=0,0472)$ na $31^{\mathrm{a}}$ - semana, em que os machos com crista que receberam dieta com $0,90 \%$ de cálcio apresentaram maior concentração de células 


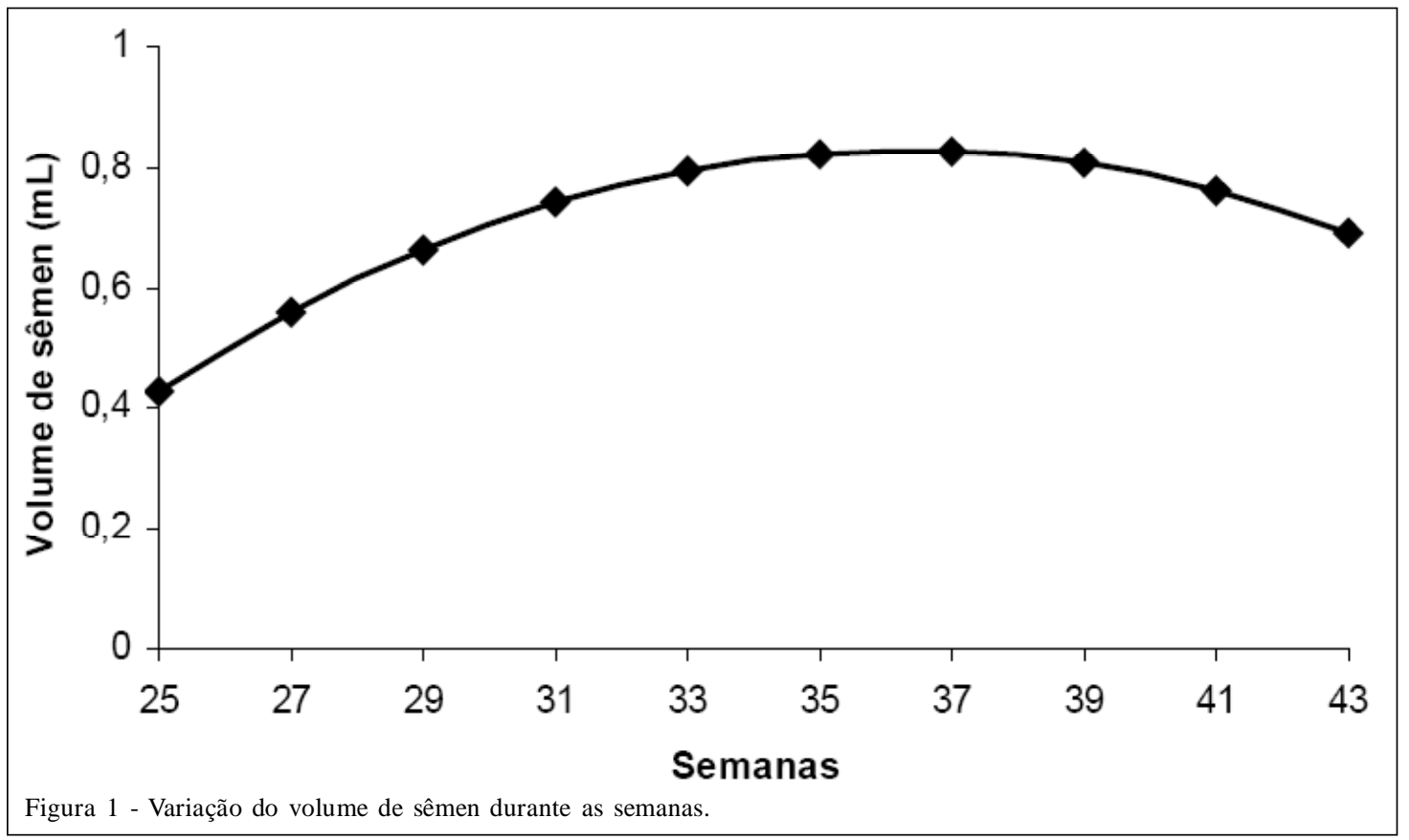

espermáticas em comparação com os galos com dieta de $0,90 \%$ de cálcio e sem crista. Os machos com dieta de $1,35 \%$ de cálcio com crista inteira e com corte da crista não se diferençaram dos tratados com $0,90 \%$ de cálcio e com crista inteira e com corte da crista (Tabela 2). Pode-se sugerir que os machos do tratamento com $0,90 \%$ de cálcio com corte de crista atingiram o pico de produção de células espermáticas antes dos machos do tratamento com $0,90 \%$ de cálcio sem corte de crista. Após esse pico de produção, houve um decréscimo acentuado. Esse decréscimo coincidiu com o pico de produção dos machos que receberam dieta com $0,90 \%$ de cálcio e com crista intacta, causando a diferença significativa. Níveis de 0,75 a 1,0\% de cálcio em dietas separadas entre sexos não alteram a produção de células espermáticas (ELGUEIRA, 1986; MCDANIEL et al., 1985; LEESON \& SUMMERS, 2000).

No estudo de interação, a fertilidade apresentou diferença $(\mathrm{P} \leq 0,05)$, em que os machos com dieta de $0,90 \%$ de cálcio e com corte da crista apresentaram desempenho inferior em comparação com os demais tratamentos na 44a semana de idade dos machos (Tabela 3).

Tabela 2 - Médias da concentração de células espermáticas $\left(\mathrm{mm}^{3}\right)$ versus efeito crista em relação aos níveis de cálcio (\%).

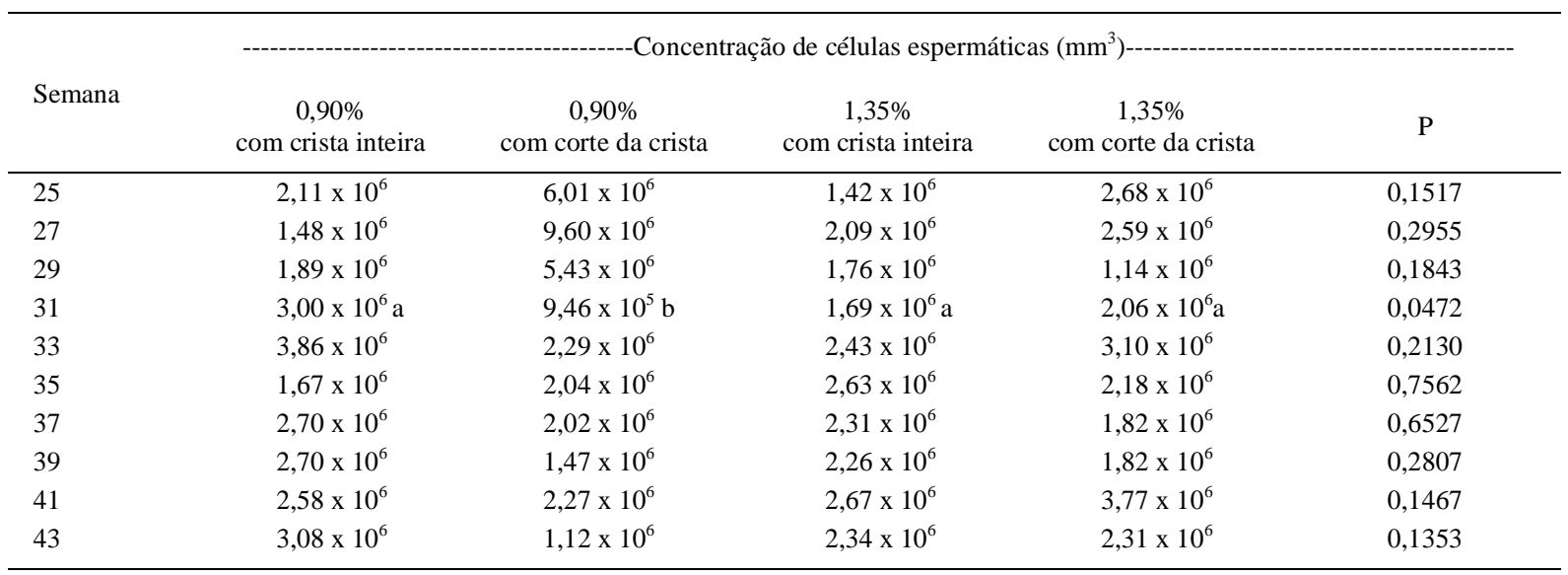

$\mathrm{a}>\mathrm{b}(\mathrm{P}<0,05)-$ Teste de Tukey.

Ciência Rural, v.40, n.10, out, 2010. 
Tabela 3 - Efeito da crista e do nível de cálcio sobre a fertilidade.

\begin{tabular}{lccccc}
\hline Semanas & $0,90 \%$ & $0,90 \%$ & $1,35 \%$ & $1,35 \%$ \\
com crista inteira & com corte da crista & com crista inteira & com corte da crista & P \\
\hline 42 & $93,94 \mathrm{a}$ & $69,42 \mathrm{a}$ & $98,77 \mathrm{a}$ & $91,99 \mathrm{a}$ & 0,0630 \\
43 & $96,43 \mathrm{a}$ & $72,02 \mathrm{a}$ & $95,80 \mathrm{a}$ & $82,14 \mathrm{a}$ & 0,2207 \\
44 & $88,36 \mathrm{a}$ & $52,62 \mathrm{~b}$ & $94,18 \mathrm{a}$ & $88,67 \mathrm{a}$ & 0,0034 \\
\hline
\end{tabular}

$\mathrm{a}>\mathrm{b}(\mathrm{P} \leq 0,05)$ - Teste de Tukey

As aves sem crista demonstram ter uma área epitelial seminífera menor que as aves com crista inteira, produzindo um número menor de células espermáticas (WILSON et al., 1988). Além disso, aves sem crista dissipam o calor de forma ineficiente (KHAN \& JOHNSON, 1970), aumentando a temperatura corporal e reduzindo assim a fertilidade. A espermatogênese é maior durante as primeiras horas do dia quando a temperatura corporal e dos testículos $\left(39^{\circ} \mathrm{C}\right)$ é menor que a média corporal (WILLIANS, 1958; TIENHOVEN, 1971).

\section{CONCLUSÃO}

Portanto, administrar a menor dose de cálcio na dieta $(0,90 \%)$ e preservar a crista intacta do reprodutor de corte se configuram na melhor relação entre nutrição e manejo, sendo suficiente para manter as variáveis peso corporal, volume de sêmen, número de células espermáticas e fertilidade em níveis adequados de produção.

\section{REFERÊNCIAS}

BRILLARD, J.P. Production de pollitos de carne por inseminación artificial. Técnicas en Avicultura, Montevideo, v.8, n.43, p.1335-1339, 1992.

DANIKOWSKI, S. et al. Influence of high levels of vitamin E on semen parameters of cocks. Journal Animal Physiology and Animal Nutrition, Munich, v.86, n.11-12, p.376-382, 2002. Disponível em: <http://www3.interscience.wiley.com/ journal/118922645/abstract?CRETRY $=1 \&$ SRETRY $=0>$. Acesso em: 08 maio, 2010. doi:10.1046/j.1439-0396.2002.00396.

ELGUEIRA, M. Alimentacion de reproductores pesados. Geórgia: Gainessville, 1986. 380p.

FERRUFINO, R.M. Retirada da crista e seus efeitos em reprodutores avícolas tipo corte. 1996. 69f. Dissertação (Mestrado em Zootecnia) - Curso de Pós-graduação em Zootecnia, Universidade Federal de Santa Maria, RS.

HONMA, N.H. Efeito dos níveis nutricionais de cálcio sobre a capacidade reprodutiva e integridade dos ossos de galos reprodutores de corte. 1992. 63f. Tese (Doutorado em Zootecnia) - Curso de Pós-graduação em Zootecnia, Universidade de Viçosa, MG.

KHAN, M.N.; JOHNSON, W.A. Physifiological response of White Leghorn layer to dubbing. Poultry Science, Savoy, v.49, p.1402, 1970.

KAPPLEMAN, J.A. et al. The effects of lour dietary calcium levels on male broiler breeders reprodution. Poultry Science, Savoy, v.61, p.1383, 1982.

LEESON, S.; SUMMERS, J.D. Broiler breeder production. Guelph: University Books, 2000. 329p.

LOGAN, V.A. Influence of cages versus floor, density, and dubbing on laing house performance. Poultry Science, Savoy, v.44, p.974-979, 1965.

LOPES, M.T. et al. Efeito do cálcio dietético sobre o desempenho reprodutivo de galos Leghorn. In: CONGESSO DE INICIAÇÃO CIENTÍFICA DA FURG-UFPEL, 2.,1993, Rio Grande, RS. Resumos... Rio Grande: FURG-UFPel, 1993. p. 244 .

MACARI, M. et al. Fisiologia aviária aplicada a frangos de corte. Jaboticabal: FUNEP/UNESP, 2002. 375p.

McDANIEL, C.D. et al. Fertility of male and female broiler breeders following exposure to elevated ambient temperatures. Poultry Science, Savoy, v.74, p.1029-1038, 1985. Disponível em: 〈http://www.ncbi.nlm.nih.gov/pubmed/7644414〉. Acesso em: 13 maio, 2010.

MARQUES, D. Manual do incubador. Amparo: CASP, 1986. $213 \mathrm{p}$.

NORRIS, L.C. et al. Effect of quantity of dietary calcium on maintenance of bone integrity in mature white Leghorn male chickens. Journal Nutrition, Florida, v.102, p.1085-1092, 1971.

ROSA, A.P. et al. Influência de intervalos da inseminação artificial e do estresse do manejo da inseminação na produção e fertilidade de fêmeas avícolas. Ciência Rural, Santa Maria, v.25, n.3, p.443-447, 1995. Disponível em: <http:// www.scielo.br/scielo.php? script $=$ sci_arttext\&pid $=$ S0 103 84781995000300020>. Acesso em: 15 maio, 2010. doi: $10.1590 / \mathrm{S} 0103-84781995000300020$.

ROSTAGNO, H.S. et al. Tabelas brasileiras para suínos e aves: Composição de alimentos e exigências nutricionais. 2.ed. Viçosa: Universidade Federal de Viçosa, 2005. 186 p. 
RUTZ, F.S. et al. Desempenho reprodutivo de galos Leghorn submetidos a diferentes níveis de cálcio dietético. Revista Brasileira de Agrociência, Pelotas, v.5, n.2, p.120-123,1999. Disponível em: <http://www.ufpel.tche.br/faem/agrociencia/ v5n2/artigo10.pdf>. Acesso em: 15 maio, 2010.

SÁ, L.M. et al. Exigências nutricionais de cálcio e sua biodisponibilidade em alguns alimentos para frangos de corte no período de 1 a 21 dias de idade. Revista da Sociedade Brasileira de Zootecnia, Viçosa, v.33, n.1, p.157-168, 2004. Disponível em: 〈http://www.scielo.br/pdf/rbz/v33n1/a20v33n1.pdf〉. Acesso em: 15 maio, 2010.

SAS InSTITUTE. SAS/STAT software: changes and enhancements through release 6.12. Cary, 1997.

SCOTT, M.L. et al. Nutrition of the chicken. 3.ed. New York: M.L. Scott and Associates, 1982. 796p.

TIENHOVEN, A. Endocrinology of reproduction in birds. In: YOUNG, W.C. Sex and internal secretions. Baltimore: Willinas and Wilkings, 1971. V.2, p.1088-1196.

TOWER, B.A. et al. Dubbling and cropping day-old Leghorn pullets. Poultry Science, Savoy, v.42, p.1032-1033, 1963.

VALLE, R. Mortalidade de matrizes em produção. In: SIMPÓSIO TÉCNICO SOBRE MATRIZES DE FRANGOS DE
CORTE, 2., 1999, Chapecó, SC. Resumos... Chapecó, SC: EMBRAPA Suínos e Aves, 1999. p.40.

VANDER, A.J. et al. Human physiology. 5.ed. Columbus: McGraw-Hill, 1990. 724p.

VARGAS JUNIOR, J.G. et al. Nutritional levels of calcium and available phosphorus for white-egg pullets and brown-egg pullets from 0 to 6 weeks of age. Revista Brasileira de Zootecnia, Viçosa, v.32, n.6, p.1919-1926, 2003. Disponível em: <http:/ / w w w. s c i e lo.br/s c i e lo.ph p p id = S 1516 $35982003000800016 \&$ script $=$ sci_arttext $\&$ tlng $=$ en $>$. Acesso em: 15 maio, 2010. doi: 10.1590/S1516-35982003000800016.

WALDROUP, P.W. Bioassays remain necessary to estimate phosphorus, calcium bioavailability. Feedstuffs, Minnetonka, v.68, p.13-20, 1996. Disponível em: <http://d.wanfangdata.com.cn/ NSTLQK_NSTL_QK9882899.aspx>. Acesso em: 15 maio, 2010.

WILSON, H.R. et al. Reproduction in white Leghorn males fed various levels of dietary calcium. Poultry Science, Savoy, v.48, p.798-801, 1969.

WILSON, JR. et al. Correlation of broiler breeder male semen production and testes morphology. Poultry Science, Savoy, v.67, p.660-668, 1988. Disponível em: <http://www.ncbi.nlm.nih.gov/ pubmed/3405945>. Acesso em: 15 maio, 2010. 